EARLY CHILDHOOD BEHAVIOURS, SCHOOLING AND LABOUR MARKET OUTCOMES: ESTIMATES FROM A SAMPLE OF TWINS*

by

Anh T. Le

Business School

The University of Western Australia

Paul W. Miller

Business School

The University of Western Australia

Andrew C. Heath

Department of Psychiatry and Siteman Cancer Center

Washington University

Nick Martin

Queensland Institute of Medical Research

JEL Code: J24, J29, J31

Key Words: Childhood Behaviours, Educational Attainment, Unemployment, Employment, Wages.

* Miller and Le acknowledge financial assistance from the Australian Research Council. This work was also supported by NIH grants AA07728, AA09022, AA10249, AA11998 (to Heath), as well as grants \#951023 and \#981351 from the National Health and Medical Research Council (to Martin). We would also like to thank the Australian Twin registry and the twins themselves for participating in this research, Nathan Gillespie for computer code that assisted with the development of the measures of conduct disorder, and two anonymous referees for helpful comments. 


\title{
EARLY CHILDHOOD BEHAVIOURS, SCHOOLING AND LABOUR MARKET OUTCOMES: ESTIMATES FROM A SAMPLE OF TWINS
}

\begin{abstract}
This paper examines the links between childhood conduct disorder problems and schooling and labour market outcomes net of genetic and environmental effects. The results show that individuals who experienced conduct disorder problems are more likely to leave school early, have poorer employment prospects and lower earnings. These findings are shown to be due to the genetic and environmental influences that are generally not considered in studies of schooling and labour market outcomes.
\end{abstract}




\section{EARLY CHILDHOOD BEHAVIOURS, SCHOOLING AND LABOUR MARKET OUTCOMES: ESTIMATES FROM A SAMPLE OF TWINS}

\section{INTRODUCTION}

Studies of school leaving decisions have canvassed a wide range of potential determinants. The most recent studies in Australia, for example, by Long et al. (1999), Marks et al. (2000) and Le and Miller (2003), have shown how school leaving decisions are related to the type of school attended, early childhood achievements in literacy and numeracy, and family background factors, including family size, family wealth, language characteristics, parents' levels of education and father's occupational status. The strongest predictors of the likelihood of completing year 12 are early childhood achievements in literacy and numeracy. This is consistent with the findings reported in studies of twins, where up to 65 percent of the variance in educational attainments has been attributed to genetic factors (Baker et al. 1996, Miller et al. 2003).

While there is reasonable agreement among these studies on the factors affecting school leaving decisions ${ }^{1}$, the understanding of these decisions is still far from complete. At a time when there is considerable emphasis on education in the knowledge economy, around one quarter of teenagers in Australia do not complete high school. Why do this sizeable group of teenagers depart from the norm on such an important decision that will help shape their future?

Examination of school completion rates for given levels of ability, or among low socio-economic status groups, reveals considerable variation. This is consistent with the relatively low degrees of explanation of the models of school leaving decisions discussed above. Other factors are presumably at work? One such set of factors may be childhood behaviours. Among these are truancy, bullying and deviant behaviour.

\footnotetext{
${ }^{1}$ Similarly, there was agreement among earlier studies of school leaving decisions in Australia. See, for example, Miller and Volker's (1989) discussion of the similarities between their findings and those reported by Williams et al. (1987).
} 
These behaviours are identifiable, measurable, and, according to the limited literature available, likely to have significant adverse consequences on school leaving decisions.

Moreover, it is possible that these behaviours also impact on the patterns of success and failure in the labour market in the post-school period. This might occur where the behaviours persist (for example, where aggression at school carried over to aggression in the workplace) or where the childhood events are associated with a permanent scar to the individual's employment record in the same way that teenage unemployment has been argued to permanently disadvantage people when older (e.g., Australian Institute of Multicultural Affairs 1985). ${ }^{2}$

This paper presents evidence on the links between childhood behaviours and school leaving decisions and labour market outcomes in Australia. It shows that adverse childhood behaviours are linked to early school leaving as well as to poor labour market outcomes. Particular childhood behaviours that are associated with the decision to leave school early are identified and ranked in importance. The extent to which the links between childhood behaviours and school learning decisions and labour market outcomes are in fact attributable to ability and family background factors is assessed using information on twins. The structure of the paper is as follows. Section II reviews the literature that has attempted to quantify the links between childhood behaviours and schooling and labour market outcomes. The data set used in the empirical work is introduced in Section III, while the statistical analyses are presented in Sections IV and V. Section VI contains a summary and conclusion.

\section{LITERATURE REVIEW}

Children can experience a range of behavioural problems, including conduct disorder, personality disorder, delinquency and immaturity that have the potential to affect their

\footnotetext{
${ }^{2}$ The Australian Institute of Multicultural Affairs (1985, p.61) argues that “....young people who suffer long initial periods of unemployment (and thus have limited work experience) tend to have more difficulty in obtaining employment when older - a finding supporting the existence of what has been called the 'scar' effect."
} 
educational outcomes. This is for several reasons, including impacts on academic performance, aggressive behaviour and adolescent delinquency, more, and more frequent, problems with teachers and other school authorities, association with the wrong people and general alienation from school.

Quay (1978) classified these behavioural problems into four major groups, namely Conduct Disorder, Personality Disorder, Inadequacy-Immaturity Syndrome and Socialised or Subcultural Delinquency. Characteristics associated with Conduct Disorder include disobedience, disruptiveness, fighting, defiance of authority, quarrelsomeness, dislike for school and destructiveness of property. The typical characteristics associated with Personality Disorder, as characterised by Quay (1978), include shyness, anxiety, a lack of self-confidence, crying, sensitivity, worrying and inability to have fun. Individuals suffering from Inadequacy-Immaturity syndrome typically exhibit short attention span, daydreaming, excessive giggling and being easily flustered and confused. Individuals who are categorised as exhibiting Socialised or Subcultural Delinquency characteristics are generally the product of their environment. Typical behaviours include gang activities, cooperative stealing, habitual truancy, and being accepted by and identified with a delinquent subgroup. While each of these behavioural problems has been shown to be important to a range of childhood and young adult outcomes, this study focuses on Conduct Disorder, which is the behavioural problem most commonly anaylsed.

A number of studies have documented links between Conduct Disorder and schooling outcomes. Fergusson and Horwood (1998), for example, show that general conduct problems identified when individuals were eight years old increased their risk of leaving school without qualifications (i.e., left school at 18 years and failed to obtain a grade $\mathrm{C}$ or better in at least one School Certificate subject). This effect did not differ significantly between males and females.

The age of onset of the childhood Conduct Disorder problems and whether these persist both seem to be important. Farmer (1995), for example, shows that contrary to expectations, boys who were first identified as having problems at age 16 left school 
earlier and had a lower level of qualification than those who were first identified as having problems at age seven. However, boys whose anti-social behaviours were first identified at age 16 attained a higher level of qualification than those who first exhibited these problems at age seven or 11 and whose behaviours persisted to age 16 . Farmer (1995) argues that it is temporal proximity to the school leaving decision rather than persistence of behaviours that is the main concern. ${ }^{3}$

More specific measures of Conduct Disorder are examined by a number of studies. Rumberger (1995) shows that students who misbehaved had a higher probability of dropping out at grade eight. Cairns et al. (1989) find that aggressive behaviour increased the likelihood of both males and females dropping out of school before completing year 11. Aggressive behaviour identified when males were in grade one reduced the likelihood that they complete high school. Among females, early aggressive behaviour did not appear to affect schooling outcomes.

The cumulative effects of childhood behavioural problems have also been investigated. Jimerson et al. (2000) argue that dropping out of school is a developmental process that begins before the individual enters elementary school and continues through to the time the individual formally withdraws from school. They therefore considered measures of problem behaviours when the child was in grades one and six and when the child was 16 years old. They found that problem behaviours reported when individuals were in the first grade and when they were 16 years old were significantly associated with high school dropout status at age 19. Problem behaviours reported when the individuals were in the sixth grade, however, did not significantly affect high school status when they were 19 years old.

Childhood behavioural problems can also impact on labour market outcomes (e.g., the probability of being employed or unemployed, unemployment duration, earnings), and these potential channels of influence have been examined by Caspi et al. (1998)

\footnotetext{
${ }^{3}$ Farmer (1995, p.630) concludes that "persistence exacerbated the negative outcome associated with temporal proximity".
} 
and Fergusson and Horwood (1998) for New Zealand, and Gregg and Machin (2000) and Feinstein (2000) for the UK, among others.

Caspi et al. (1998) suggest that the impact of antisocial behaviours on labour market outcomes, such as unemployment, may reflect a combination of three processes. First, they may reflect the behavioural syndrome of non-conformity that is expressed through involvement in deviant behaviours and rejection of conventional values such as employment. Second, antisocial youths may be selected into jobs that have high rates of turnover. Finally, antisocial youths may get into trouble in the workplace because their behaviour affects their job performance, relations with coworkers and supervisors.

Fergusson and Horwood (1998) show that early conduct problems at age eight were associated with an increased risk of being unemployed after leaving school. However, after controlling for adolescent behavioural factors (e.g., truancy, cannabis use), early conduct problems were not related to unemployment. The key factors at adolescence that affect unemployment were delinquent peer affiliation and truancy. Similarly, Caspi et al. (1998) show that while Conduct Disorder reported between ages seven and nine significantly increased the risk of becoming unemployed, its impact was smaller than that of Conduct Disorder behaviours at age 15. Caspi et al. (1998) also found that adolescents who were involved in antisocial behaviour were at high risk of being unemployed regardless of their school leaving age. ${ }^{4}$ This appeared to be because antisocial characteristics affect job search and job performance, and this reduced the individual's ability to locate and retain stable employment during the transition into adulthood. Gregg and Machin (2000) also found that those with low school attendance or those who had contact with the police had longer durations of unemployment.

\footnotetext{
${ }^{4}$ In addition to the above behavioural problems, Caspi et al. (1998) found that individuals who exhibit Immaturity-Inadequacy Syndrome between the ages of three and five were more likely to be unemployed and to have longer durations of unemployment.
} 
Differences exist between males and females in relation to the behavioural problems that influence their employment outcomes. Feinstein (2000) shows that boys who were involved in antisocial activities at age 10 were more likely to experience shortterm unemployment (unemployed for between four months and 12 months) than those who did not engage in these activities. However, antisocial behaviours did not affect long-term unemployment (unemployed for more than one year) among boys. Feinstein (2000) suggests that boys with high antisocial scores were getting jobs and then losing them. Among females, antisocial behaviour was not a strong predictor of short-term or long-term unemployment.

Studies that examine the link between childhood behavioural problems and earnings reveal a number of interesting, and possibly counter-intuitive, findings. Feinstein (2000), for example, reports that Conduct Disorder had a strong positive effect on the earnings of females. However, Conduct Disorder has no impact on the earnings of males.

In summary, when behavioural problems variables are modeled in conjunction with other factors that affect schooling outcomes, such as sociodemographic background, family background, academic background and individual characteristics, the behavioural problems variables are shown to be major determinants of schooling outcomes. In addition, it appears that adolescent behavioural problems have a more influential negative impact on schooling outcomes than early childhood behavioural problems. Childhood behavioural problems are also shown to affect labour market outcomes. While such problems are typically associated with lower rates of employment, some of the empirical studies report positive links between adverse childhood behaviour and earnings. The extent to which these relationships are due to genetic and environmental factors has not been explored in the literature. This shortcoming is addressed in the analyses presented below.

\section{DATA}

The data analysed in this study were obtained from members of the young adult cohort of the Australian Twin Register. They constitute a volunteer twin panel born 
between 1961-1974. Nearly all were first registered with the panel between 1980 and 1982 by their parents. A total of 4,264 twin pairs were recruited at this time.

The data were collected by means of a telephone interview conducted by lay interviewers. The individual response rate for these telephone interviews was over 80 percent. Individuals were excluded from the study where they did not answer questions on any of the variables used in the analysis. A sample of 6,265 results.

The Australian Twins Registry contains information on family background, demographic, labour market and behavioural variables. The information on childhood behaviour covers a wide range of behavioural problems, such as misbehaviour in school, being suspended or expelled from school, truancy, bullying, minor theft, serious robbery (e.g., steal money or property using force), property damage, break and entry, arson and physical violence.

These data are used in two ways. First, the sample is used as if it was a sample of individuals. This enables clear links to be established with the Australian and wider literature on school leaving decisions and labour market outcomes that has been largely based on studies of individuals. Second, the twins dimension of the data set is exploited to show whether the relationships between conduct disorder and schooling decisions and labour market outcomes are due to genetic and environmental factors.

To provide a link with previous Australian research, and to provide a test of the integrity of the Twins data for study of school leaving decisions, the Twins data are compared with data from two cohorts of the Youth in Transition survey. ${ }^{5}$ The median year of birth for members of the Twins data is 1967/1968, with a range from 1961 to 1974. Hence the data from the 1961 and 1970 cohorts of the Youth in Transition survey analysed by Le and Miller (2003) offer a useful benchmark.

\footnotetext{
${ }^{5}$ The Youth in Transition data comprise longitudinal surveys of individuals in Australia born in 1961, 1965, 1970 and 1975. For the 1961 cohort, data were collected for the period 1978 to 1994 . For the 1970 cohort, data were collected for the period 1985 to 1994 . These data contain information on the final year of school as well as the first few years of labour market activities.
} 
Table 1 lists means and standard deviations of a number of variables. Overall, the data in the table show that there are a number of similarities in the characteristics of individuals from the Twins data and those from the 1961 and 1970 cohorts. For example, the data show that the percent of fathers possessing a post-secondary qualification is greater than that of mothers having the same education level in each data set. Individuals from the Twins data and from the 1961 and 1970 cohorts have between two and three siblings.

There are two distinguishing features of the Twins data that should be noted. First, there are more females in the Twins data than in the 1961 and 1970 cohorts. Miller et al. (1995) note that samples of twins tend to have this characteristic. Second, early school leaving, at 20 percent, is less prevalent in the Twins data than in the Youth in Transition data (45 percent and 30 percent). ${ }^{6}$ Again, this appears to be a special feature of many samples of Twins (Miller et al. 1995).

Table 1

Means and Standard Deviations of Variables

\begin{tabular}{lrrrrrr}
\hline & \multicolumn{3}{c}{ Twins Data } & \multicolumn{1}{r}{ 1961 Cohort } & \multicolumn{2}{r}{ 1970 Cohort } \\
\hline Variable & Mean & Std.Dev & Mean & Std.Dev & Mean & Std.Dev \\
Early school leavers & 20.40 & 40.30 & 44.73 & 49.73 & 30.46 & 46.04 \\
Father's post-secondary qualification & 22.45 & 41.73 & 15.02 & 35.73 & 29.01 & 45.39 \\
Mother's post-secondary qualification & 17.94 & 38.37 & 8.88 & 28.36 & 22.93 & 42.05 \\
Number of siblings & 2.35 & 1.85 & 2.86 & 1.96 & 2.40 & 1.61 \\
Female & 55.46 & 49.71 & 48.86 & 49.99 & 51.35 & 49.99 \\
& & & & & & \\
Sample size & 5687 & & 3996 & & & \\
\end{tabular}

The data sets used in Table 1 were used to estimate a simple model accounting for variation in the probability of being an early school leaver. This model relates the early school leaving rate to age, gender, the parents' post-secondary qualification and the number of siblings. The results are presented in Table 2. In these analyses, the Twins data are used as if they were from a sample of unrelated individuals. It is noted that the late 1970s and early 1980s when these groups were making their school leaving decisions were periods of considerable change in schooling behaviour. This

\footnotetext{
${ }^{6}$ As the Twins data set does not distinguish between year 11 and year 12 completion, the focus of the analyses presented here is on early school leaving, defined as leaving at year 10 or earlier, rather than on the year 12 completion rate.
} 
is evident from the strong reduction in the extent of early school leaving illustrated in Table 1. The determinants of school leaving decisions also changed considerably over this period, and this has been analysed by Le and Miller (2003). Hence, the comparative assessment offered here places most emphasis on the broad patterns in the data.

Overall, the Table 2 results are robust across data sets with regard to the direction of the impact of the explanatory variables on the early school leaving rate and the level of significance. There are a number of important features that can be noted. First, female students have a lower probability of leaving school early than male students. Second, the probability of being an early school leaver is negatively related to the parents' post-secondary education. The impact of the father's post-secondary qualification is particularly strong. For example, having a father who has a postsecondary qualification decreases the chances of individuals leaving school early by 21 percentage points in the Twins data, 26 percentage points in the 1961 cohort and 14 percentage points in the 1970 cohort. $^{7}$ In comparison, the impact of the mother's post-secondary qualification on the probability of leaving school early is weaker, being 17 percentage points and 15 percentage points, respectively, for individuals in the Twins data and 1961 cohort. $^{8}$ Third, having a sibling increases the probability of being an early school leaver by between one and three percentage points.

There are a number of patterns to the Table 2 results across data sets. The sibling and gender effects obtained from the Twins data set are within the range of effects obtained using the Youth in Transition data. However, the effects for parents'

\footnotetext{
7 The partial effects of explanatory variables on the probability of leaving school early can be computed as $\frac{\partial S}{\partial X_{k}}=S(1-S) \hat{\beta}_{k}$ where $S$ is the early school leaving rate, $X_{k}$ is the $\mathrm{k}^{\text {th }}$ explanatory variable and $\hat{\beta}_{k}$ is the associated estimated coefficient. The partial effects are evaluated at the sample mean early school leaving rates (20.40 percent for the Twins data, 44.73 percent for the 1961 cohort and 30.46 percent for the 1970 cohort). For binary explanatory variables these partial effects will only be an approximation.

${ }^{8}$ For the 1970 cohort, the partial effect of mother's post-secondary qualification on the probability of leaving school early is similar to that of father's qualification.
} 
education for individuals in the Twins data are slightly larger in absolute value than the comparable effects in the Youth in Transition data. ${ }^{9}$

Table 2

Logit Estimates of the Probability of Early School Leaving

\begin{tabular}{|c|c|c|c|c|c|c|}
\hline \multirow{2}{*}{ Variable } & \multicolumn{2}{|c|}{ Twins Data } & \multicolumn{2}{|c|}{1961 Cohort } & \multicolumn{2}{|c|}{1970 Cohort } \\
\hline & Coeff. & t-ratio & Coeff. & t-ratio & Coeff. & t-ratio \\
\hline Constant & -2.643 & 6.32 & -0.266 & 3.89 & -0.693 & 6.57 \\
\hline Age & 0.051 & 3.70 & - & - & - & - \\
\hline Female & -0.180 & 2.65 & -0.070 & 1.07 & -0.402 & 4.12 \\
\hline Father's post-secondary qualification & -1.304 & 10.15 & -1.061 & 9.55 & -0.657 & 5.25 \\
\hline Mother's post-secondary qualification & -1.070 & 7.48 & -0.606 & 4.32 & -0.643 & 4.58 \\
\hline Number of siblings & 0.061 & 3.51 & 0.096 & 5.64 & 0.144 & 4.93 \\
\hline$\chi^{2}(5)$ & 365.40 & & & & & \\
\hline$\chi^{2}(4)$ & & & 218.68 & & 129.48 & \\
\hline McFadden $R^{2}$ & 0.06 & & 0.04 & & 0.05 & \\
\hline Sample size & 5687 & & 3996 & & 2109 & \\
\hline $\begin{array}{ll}\text { Note: } & \text { The McFadden } \mathrm{R}^{2} \text { is calcul } \\
& \text { of the model and } l_{o}=\text { the log } \\
& \text { zero (see Veall and Zimmerl }\end{array}$ & $\begin{array}{l}\text { S } 1-(l \\
\text { ihood } \\
1996) .\end{array}$ & if $t$ & $\begin{array}{l}l_{m}=\text { the } \\
\text { on-inter }\end{array}$ & $\begin{array}{l}\text { ximis } \\
\text { coef }\end{array}$ & $\begin{array}{l}\text { og-likel } \\
\text { nts are }\end{array}$ & $\begin{array}{l}\text { od valu } \\
\text { tricted }\end{array}$ \\
\hline
\end{tabular}

These comparisons of means and regression results for the Twins data with the Youth in Transition data show that while the Twins data set is a purposive sample, the patterns in relation to school leaving decisions are broadly similar to those obtained from samples representative of comparable segments of the general population (i.e., the 1961 and 1970 birth cohorts). The Twins data set therefore should provide a reasonable basis for the investigation of the links between conduct disorder and school leaving decisions. ${ }^{10}$

\section{SCHOOL OUTCOMES}

The model of early school leaving considered in this paper is expressed as:

$$
S_{i}^{*}=X_{i} \beta+\gamma \text { Ability }_{i}+\delta F B G_{i}+\varepsilon_{i}
$$

where $S^{*}$ is a latent (unobserved) variable that captures the propensity towards leaving school at year 10 or earlier of individual $i, X$ is a row vector containing age, gender, parents' post-secondary qualification, number of siblings and information on

\footnotetext{
${ }^{9}$ It could be argued that this represents compensatory behaviour on the part of parents of twins.

${ }^{10}$ Analyses of the income data in this data set by Miller et al. (2003) reveals patterns similar to those found in the random samples from the 1991 Australian Census of Population and Housing.
} 
behavioural problems, Ability is the individual's innate ability, and $F B G$ is the family background influences that impact on school leaving decisions over and above those related to parents' educational attainment and family size. Included in $F B G$ would be family income, levels of parental encouragement and involvement in school activities. $\beta$ is a column vector of coefficients, $\gamma$ and $\delta$ are scalar coefficients, and $\varepsilon$ is a stochastic disturbance term. ${ }^{11}$ Two observable outcomes may be derived from $S^{*}$ with reference to an arbitrary threshold of zero. Thus, the individual is held to have left school early $(S=1)$ where $S^{*}$ exceeds zero and did not leave school early $(S=0)$ otherwise. This observed indicator variable $(S)$ becomes the dependent variable in the analysis for individual $i$. In this paper the estimates of $\beta$ will be obtained using logit estimation.

In many of the analyses in the literature, information on ability and family background is omitted from the specification of the estimating equation. In other studies, proxies for these are used. In this study we conduct a conventional "twins" analysis to obtain estimates of the links between conduct disorder (one of the elements of the vector of explanatory variables, $X$ ) and early school leaving behaviour that are not biased through the omission of (or the use of poor proxies for) the ability and family background factors.

The way in which this is done is best seen by rewriting the model as:

$$
S_{i j}=X_{i j} \beta+\mu_{j}+\varepsilon_{j}
$$

where $j$ is the subscript for the family and $i$ is the subscript for the individual in family $j . \quad \mu_{j}$ is a fixed effect for the $j^{\text {th }}$ family.

If equation (2) is estimated on a sample of identical twins who were raised together then the fixed effects, $\mu_{j}$, will capture both the Ability and $F B G$ terms of equation (1) (along with the influence of parents' educational attainment and the number of

\footnotetext{
${ }^{11}$ Appendix A contains definitions of the variables used in the analyses, as well as the means and standard deviations of these variables for the samples of males and females.
} 
siblings). The estimate of $\beta$ will be free of bias associated with the omission of these factors when equation (1) is estimated using a sample of individuals.

Non-identical twins are no more genetically alike then ordinary siblings. Hence, if equation (2) is estimated on a sample of non-identical twins who were raised together, then the fixed effects, $\mu_{j}$, will capture the $F B G$ term of equation (1) (again, along with the influence of parents' educational attainment and the number of siblings). It will not capture the influence of ability, as this can vary between the non-identical twins in family $j$. Thus, the estimates of $\beta$ will be free of bias associated with the omission of $F B G$ from equation (1) but will be biased by the absence of a suitable control for ability in the estimating equation.

Thus, estimates obtained from samples of identical and non-identical twins using this fixed effects model can be compared to examine the way in which ability impacts on school leaving decisions through the conduct disorder variables. In turn, estimates obtained from a sample of non-identical twins can be compared with estimates obtained from a sample of individuals to assess the way that family background factors influence school leaving decisions through the conduct disorder variable.

The conduct disorder variables used in this study are based on the number of separable 'conduct disorder' problems (e.g., stealing, truancy) experienced by the individual. $^{12}$ Two measures are formed: the first is distinguished by a requirement that several of the 'conduct disorder' problems commence before the age of 13, whereas the second does not have any such age requirement. This is consistent with Farmer's (1995) finding that temporal proximity of the existence of the behavioural problem to the school leaving decision is quite important.

\footnotetext{
${ }^{12}$ These measures of behavioural problems focus on Conduct Disorder and Socialised or Subcultural Delinquency. Appendix A contains further details on these. For presentation purposes, these measures will be referred to as 'conduct disorder'.
} 
Table 3 presents frequencies on two summary measures of 'conduct disorder', termed CONDUCT1 and CONDUCT2. The difference between CONDUCT1 and CONDUCT2 is that the latter include variables that take into account problem behaviours that do not require the onset to be before 13 years of age. The data show that between 49 percent and 67 percent of individuals do not experience any 'conduct disorder' problems. However, there are a large number of individuals who experience either one (between 18 percent and 24 percent), two (between seven percent and 13 percent) or three (between four percent and seven percent) separate 'conduct disorder' problems. Only a small proportion of individuals experiences more than four separate 'conduct disorder' problems.

Table 3

Frequencies of Summary Measures of Behavioural Problems

\begin{tabular}{lrr}
\hline Number of conduct disorder problems & CONDUCT1 (\%) & CONDUCT2 (\%) \\
\hline 0 & 67.38 & 48.90 \\
1 & 18.22 & 23.53 \\
2 & 7.33 & 13.15 \\
3 & 3.62 & 6.86 \\
4 & 1.74 & 3.69 \\
5 or more & 1.71 & 3.88 \\
& & \\
Total (\%) & 100.00 & 100.00 \\
\hline
\end{tabular}

The logit estimates of the probability of leaving school early for males and females are presented in Table $4 .{ }^{13}$ Column (i) contains results from the benchmark model similar to that reported in Table 2. Column (ii) contains results for models that include the encompassing measures of 'conduct disorder' (CONDUCT2). The nonlinear nature of the 'conduct disorder' scale is examined in column (iii).

Overall, the results in columns (ii) and (iii) following the inclusion of the conduct disorder variable for both males and females relating to age, gender, parents' education and siblings do not differ from those reported for the benchmark model (column i). Hence the discussion will focus on the impacts of 'conduct disorder' variables on the probability of leaving school early.

\footnotetext{
${ }^{13}$ The $\chi^{2}$ tests of whether the data for males and females could be pooled and a single equation estimated indicated that these samples should be examined separately.
} 
Table 4

Logit Estimates of the Probability of Early School Leaving-Males and Females

\begin{tabular}{|c|c|c|c|c|c|c|}
\hline \multirow[b]{2}{*}{ Variable } & \multirow[b]{2}{*}{ Coeff. } & \multicolumn{2}{|c|}{ MALES } & \multicolumn{3}{|c|}{ FEMALES } \\
\hline & & Coeff. & Coeff. & Coeff. & Coeff. & Coeff. \\
\hline & (i) & (ii) & (iii) & (i) & (ii) & (iii) \\
\hline Constant & -2.521 & -2.934 & -2.927 & -2.901 & -3.388 & -3.368 \\
\hline Age & 0.049 & 0.054 & 0.053 & 0.053 & 0.062 & 0.061 \\
\hline & $(2.37)$ & $(2.58)$ & $(2.55)$ & $(2.81)$ & $(3.25)$ & $(3.21)$ \\
\hline Father's post-secondary & -1.404 & -1.399 & -1.399 & -1.212 & -1.230 & -1.229 \\
\hline qualification & $(7.51)$ & $(7.46)$ & (7.47) & $(6.85)$ & $(6.90)$ & $(6.90)$ \\
\hline Mother's post-secondary & -0.952 & -0.968 & -0.960 & -1.205 & -1.184 & -1.188 \\
\hline qualification & $(4.96)$ & $(5.01)$ & $(4.98)$ & $(5.60)$ & $(5.48)$ & $(5.49)$ \\
\hline Number of siblings & 0.043 & 0.037 & 0.037 & 0.076 & 0.069 & 0.068 \\
\hline & $(1.70)$ & $(1.45)$ & $(1.45)$ & $(3.20)$ & $(2.87)$ & $(2.83)$ \\
\hline CONDUCT2 & n.a. & $\begin{array}{l}0.171 \\
(6.47)\end{array}$ & n.a. & n.a. & $\begin{array}{r}0.271 \\
(7.47)\end{array}$ & n.a. \\
\hline $\begin{array}{l}\text { One conduct disorder } \\
\text { problem }\end{array}$ & n.a. & n.a. & $\begin{array}{l}0.274 \\
(2.02)\end{array}$ & n.a. & n.a. & $\begin{array}{r}0.312 \\
(2.74)\end{array}$ \\
\hline $\begin{array}{l}\text { Two conduct disorder } \\
\text { problems }\end{array}$ & n.a. & n.a. & $\begin{array}{r}0.351 \\
(2.32)\end{array}$ & n.a. & n.a. & $\begin{array}{r}0.539 \\
(3.65)\end{array}$ \\
\hline $\begin{array}{l}\text { Three conduct disorder } \\
\text { problems }\end{array}$ & n.a. & n.a. & $\begin{array}{l}0.557 \\
(3.25)\end{array}$ & n.a. & n.a. & $\begin{array}{r}0.726 \\
(3.57)\end{array}$ \\
\hline $\begin{array}{l}\text { Four or more conduct } \\
\text { disorder problems }\end{array}$ & n.a. & n.a. & $\begin{array}{r}0.779 \\
(5.06)\end{array}$ & n.a. & n.a. & $\begin{array}{r}1.361 \\
(6.40)\end{array}$ \\
\hline$\chi^{2}(4)$ & 174.68 & & & 1884.74 & & \\
\hline$\chi^{2}(5)$ & & 218.35 & & & 243.00 & \\
\hline$\chi^{2}(8)$ & & & 203.72 & & & 242.61 \\
\hline McFadden $R^{2}$ & 0.07 & 0.08 & 0.08 & 0.06 & 0.08 & 0.08 \\
\hline Sample size & 2533 & 2533 & 2533 & 3154 & 3154 & 3154 \\
\hline
\end{tabular}

Note: $\quad$ n.a. $=$ Not applicable.

The McFadden $\mathrm{R}^{2}$ is calculated as $1-\left(l_{m} / l_{0}\right)$, where $l_{m}=$ the maximised log-likelihood value of the model and $l_{o}=$ the $\log$-likelihood value if the non-intercept coefficients are restricted to zero (see Veall and Zimmermann 1996). Absolute value of ' $t$ ' statistics in parentheses.

The results in column (ii) of Table 4 show that the encompassing measure of "conduct disorder' has a positive and significant impact on the probability of an individual being an early school leaver. Thus, the higher the value of CONDUCT2 (which indicates that individuals are exhibiting a large number of 'conduct disorder' problems), the more likely the individual will drop out of school early. ${ }^{14}$ This is consistent with the results from previous studies (e.g., Fergusson and Horwood 1998). While 'conduct disorder' is associated with higher probabilities of leaving school at an early age, it is useful to put this in perspective. Among the other variables included in the model, the largest partial effect is associated with the father having a post-secondary qualification. Compared to teenage boys whose fathers do not have

\footnotetext{
${ }^{14}$ Similar results are obtained when the CONDUCT1 measure is used in place of CONDUCT2.
} 
post-secondary qualifications, those whose fathers have post-secondary qualifications are 24 percentage points less likely to leave school early. ${ }^{15}$ Among teenage girls, those whose fathers possess a post-secondary qualification are 20 percentage points less likely to leave school early. ${ }^{16}$ A teenager would need to be characterised by six of the 'conduct disorder' childhood behavioural problems to be associated with the same magnitude of impact. Only a negligible fraction of the sample records a 'conduct disorder' score of this magnitude.

Hence, while the 'conduct disorder' variable is important, its impact is not overwhelming. In part this may be because of the linear functional form used. A great many of the sample ( 24 percent of males and 23 percent of females) have a value of one in the measure of 'conduct disorder', while 16 percent of males and 11 percent of females have a value of two. If low values of the 'conduct disorder' score are associated with little change in schooling behaviour, while larger values are associated with more marked changes in schooling behaviour (or vice versa), then the linear form, which ascribes the same effect of moving from zero to one as to moving from six to seven on the 'conduct disorder' scale, would be inappropriate. Hence, a series of dummy variables was created from the 'conduct disorder' (CONDUCT2) scale along the line of Gregg and Machin (2000). These are used to characterise individuals with scores of one, two, three and four or higher in comparison to individuals without any 'conduct disorder' problems.

The column (iii) results show that the probability of leaving school early increases with the number of 'conduct disorder' behaviours experienced by both males and females. Compared to males who do not experience any 'conduct disorder' problem, those who experience one, two, three, or four or more separate 'conduct disorders' are five percentage points, six percentage points, nine percentage points and 13 percentage points, respectively, more likely to be early school leavers. Among females, compared to those who do not experience any conduct disorder' problem, the

\footnotetext{
${ }^{15}$ The partial effect is estimated at the sample mean school leaving rate for males ( 21.59 percent).

${ }^{16}$ The partial effect is estimated at the sample mean school leaving rate for females (19.44 percent).
} 
early school leaving rates for those with one, two, three and four or more 'conduct disorders' are five percentage points, eight percentage points, 11 percentage points and 21 percentage points, respectively higher. While the estimated impacts in this alternative specification differ from those derived from the linear functional form, particularly at low and high numbers of 'conduct disorder' behaviours, the same conclusion can be drawn: the likelihood of leaving school early increases with the number of 'conduct disorder' problems. Moreover, it is noted that the magnitudes of three or less 'conduct disorders' are relatively small compared to those of parents' post-secondary qualification.

Some 'conduct disorder' problems may have more detrimental effects on the schooling outcomes than others. Hence models were estimated where the summary measure CONDUCT2 was replaced by a series of dummy variables recording the incidence of specific behavioural problems (results are available upon request from the authors). A ranking of the magnitude of the effects of different 'conduct disorders' on the school leaving decision reveals that, for males, stealing with confrontation has the largest effect on early school leaving (a partial effect of 27 percentage points). Other behavioural problems relating to using a weapon and deliberately skipping school (not requiring the onset to be before 13 years of age) have smaller effects on early school leaving decisions (partial effects ranging from six percentage points to eight percentage points). For female students, running away from home at night, bullying others and starting physical fights are the 'conduct disorder' problems that have the largest impacts on their early school leaving decision (partial effects ranging from nine percentage points to 21 percentage points). Other 'conduct disorder' problems that increase the chances of females being early school leavers include lying, staying out despite parental prohibition at night (not requiring the onset to be before 13 years of age) and deliberately skipping school (not requiring the onset to be before 13 years of age). However, the impacts of these 'conduct disorders' on the school leaving decisions of females are quite modest, ranging between four percentage points and six percentage points. 
The analysis of the impacts of the specific behaviour problems revealed four problems (starting physical fights, staying out later than supposed to, running away from home over night, wagging school) that had consistent effects on the schooling outcome of both males and females. Hence the model of early school leaving was re-estimated where CONDUCT2 was computed based on only these four underlying behavioural problems. The partial effects for this alternative summary 'conduct disorder' measure on the probability of leaving school early for males and females are six percentage points and seven percentage points, respectively, about three percentage points greater than when the broader measure of CONDUCT2 was used in Table 4.

These analyses provide quite compelling evidence of a positive link between the presence of conduct disorder behaviours and early school leaving. However, the link could arise because of the omission of genetic factors from the model and the narrow focus of the environmental variables. This possibility can be explored by exploiting the twin dimension of the data base.

Before presenting the results from a conventional twins analysis of the conduct disorder-early school leaving relationship, one statistical issue needs to be covered. In a logit fixed effects model, any case where the schooling outcomes of a twin and his/her co-twin are the same (that is, both are early school leavers or both are not early school leavers) needs to be omitted from the sample, as maximum likelihood estimation of the fixed effect will attempt to ascribe an undefined $( \pm \infty)$ value to the particular fixed effect. As the overall rate of early school leaving is quite low (20 percent) this means that the majority of the sample will be excluded for this reason. Accordingly, the analysis was replicated using a linear probability model where this issue does not arise. It was also replicated using a continuous education variable in place of the binary early school leaver indicator. ${ }^{17}$

\footnotetext{
${ }^{17}$ To facilitate comparison with the binary indicator of early school leaving, the continuous education variable is measured from highest to lowest.
} 
A second matter that needs to be addressed is the treatment of male-female nonidentical twins. These 'mixed' sets of non-identical twins are excluded from the sample.

Table 5 lists the coefficients on the 'conduct disorder' variable CONDUCT2 obtained from the various sets of analyses. As outlined above, the 'between-twins model' estimates are obtained by treating the sample as one of individuals. Other than for the parents' educational attainment and the number of siblings variables, the 'betweentwins models' do not control for genetic or environmental effects. The 'within-twins models' for non-identical twins effect a control for environmental factors, while the 'within-twins models' for identical twins control for both environmental and genetic factors.

The Table 5 results suggest that:

(i) taking account of environmental factors other than the parental and family size information already incorporated into the model of early school leaving behaviour through the within-twins analysis for non-identical twins does not dampen the early school leaving-conduct disorder relationship. The larger effect for non-identical twins in the fixed effects logit models appears to be associated with a stronger relationship between early school leaving and 'conduct disorder' in the subset of the non-identical twins analysed rather than from a perverse association between 'conduct disorder' and family background. This is illustrated by the findings for the linear probability and continuous education variables where all twins rather than just those with dissimilar schooling outcomes are included in the analysis;

(ii) genetic factors appear to be responsible for all of the apparent positive links between conduct disorder behaviours and early school leaving behaviour. In other words, once both family environment and particularly genetic factors are held constant through the within-twins analyses conducted on identical twins, the conduct disorder-early school leaving behaviour relationship is statistically insignificant for both males and females. This finding emerges from each of the sets of analyses undertaken. 
Table 5

Results From Fixed Effects Models of Effects of Conduct Disorder on Schooling Outcomes -Males and Females

\begin{tabular}{lrrr}
\hline Logit: Males & & & \\
& Between-Twins Model & Within-Twins Models \\
\hline & $\ldots . .1$ Individuals & Identical Twins & Non-identical Twins \\
Coefficient & $0.171(6.47)$ & $-0.099(0.39)$ & $0.382(2.17)$ \\
Partial effect & $0.029(6.47)$ & $-0.025(0.39)$ & $0.096(2.17)$ \\
Sample size & 2533 & 100 & 152
\end{tabular}

Linear Probability: Males

\begin{tabular}{|c|c|c|c|}
\hline \multicolumn{2}{|r|}{ Between-Twins Model } & \multicolumn{2}{|r|}{ Within-Twins Models } \\
\hline & Individuals & Identical Twins & Non-identical Twins \\
\hline Coefficient & $0.030(6.66)$ & $-0.003(0.27)$ & $0.021(1.68)$ \\
\hline Sample size & 2533 & 796 & 674 \\
\hline \multicolumn{4}{|c|}{ Continuous Education: Males } \\
\hline & Between-Twins Model & & Within-Twins Models \\
\hline & Individuals & Identical Twins & Non-identical Twins \\
\hline Coefficient & $0.217(7.68)$ & $-0.096(1.37)$ & $0.171(2.31)$ \\
\hline Sample size & 2533 & 796 & 674 \\
\hline
\end{tabular}

\begin{tabular}{|c|c|c|c|}
\hline \multicolumn{4}{|l|}{ Logit: Females } \\
\hline & Between-Twins Model & & Within-Twins Models \\
\hline & Individuals & Identical Twins & Non-identical Twins \\
\hline Coefficient & $0.271(7.47)$ & $0.393(1.62)$ & $0.501(2.37)$ \\
\hline Partial effect & $0.042(7.47)$ & $0.098(1.62)$ & $0.125(2.37)$ \\
\hline Sample size & 3154 & 196 & 160 \\
\hline
\end{tabular}

Linear Probability: Females

\begin{tabular}{lrrr} 
& \multicolumn{2}{c}{ Between-Twins Model } & Within-Twins Models \\
\hline & Individuals & Identical Twins & Non-identical Twins \\
Coefficient & $0.047(7.88)$ & $0.021(1.33)$ & $0.037(2.33)$ \\
Sample size & 3154 & 1164 & 898
\end{tabular}

Continuous Education: Females

\begin{tabular}{lcrr} 
& \multicolumn{2}{c}{ Between-Twins Model } & Within-Twins Models \\
\hline & Individuals & Identical Twins & Non-identical Twins \\
Coefficient & $0.322(8.25)$ & $0.126(1.26)$ & $0.248(2.46)$ \\
Sample size & 3154 & 1164 & 898 \\
\hline
\end{tabular}

Note: Absolute value of ' $t$ ' statistics in parentheses.

There are several caveats related to measurement error that need to be introduced in relation to these results. Errors of measurement have the potential to constitute a greater problem in the fixed effects estimator than with the estimators applied to a sample of individuals because of the correlation between the measures of a variable for a twin and his/her co-twin (see Griliches 1979). This issue has been discussed in detail in the twins literature in relation to schooling variables, and similar issues arise in relation to the conduct disorder variable that is the focus of the current study. This 
literature has also been concerned with the possibility that the within-twins estimator does not fully eliminate the omitted ability variable in equation (1) (Griliches 1979, Neumark 1999). Individual components of ability can lead the within-twins estimator applied to identical twins to be biased.

It is also to be noted that where the source of variation in problem behaviours is mainly across rather than within families, the use of the within-twins estimator will exacerbate the attenuation bias associated with the measurement error. ${ }^{18}$ Fully threequarters of the variation in the measure of conduct disorder is from across families. Part of the diminution of the effects of conduct disorder on schooling outcomes in the within-twins estimator in Table 5 may therefore arise from this source.

Standard within-twins IV estimators can, in principle, be applied in response to this problem, though the efficacy of these have been questioned in the recent literature (see Bound and Solon 1999, Neumark 1999 and Black, Berger and Scott 2000). The absence of suitable instruments, however, precludes satisfactory application in the current analysis. Future data collection will need to address this problem.

\section{LABOUR MARKET OUTCOMES}

As well as affecting school leaving decisions, childhood behaviours may affect adult outcomes. This has long been recognised in the behavioural genetics literature (e.g., Lynskey et al. 2002, Nelson et al. 2002). The potential for childhood behaviours to impact on an individual's outcomes in the labour market has also been examined in several studies (e.g., Farmer 1995, Fergusson and Horwood 1998, Gregg and Machin 2000, Feinstein 2000).

Two possible pathways through which 'conduct disorder' might impact on labour market outcomes are considered in this study. First, it is possible that childhood 'conduct disorder' will impact on the chances that a person will be employed. For example, early behaviours such as truancy might carry across to adulthood, resulting

\footnotetext{
${ }^{18}$ We thank a referee for this point.
} 
in problems obtaining stable employment (Gregg and Machin 2000, Caspi et al. 1998). Second, among those who are employed, childhood 'conduct disorder' may impact on the wage obtained (e.g., Gregg and Machin 2000, Feinstein 2000).

Each of these potential avenues of influence is explored below. The starting point for the study is the estimation of a model of labour market outcomes, augmented by a variable for 'conduct disorder'. Labour market outcomes in this instance are recorded at the time of the last interview: around 1995 when the members of the sample were between 21 and 34 years. The distribution of individuals across labour market states can be examined within a logit framework where the probability that individual $i$ with characteristics $Z_{i}$ will be employed can be expressed as:

$$
E_{i} \mid Z_{i}=\frac{1}{1+e^{-\delta Z_{i}}}
$$

where $E$ is the probability that an individual with observed characteristics $Z$ will be employed and $\delta$ is a vector of coefficients to be estimated. The unemployed and nonlabour force categories are pooled in this estimation as each has a relatively small representation (3.6 percent of the sample unemployed and 14.6 percent of the sample not in the labour force) and because the thresholds between them are generally not clearly defined. A fixed effects version of this employment model analogous to equation (2) can be estimated using non-identical and identical twins to provide information on environmental and genetic influences, respectively.

The model of earnings estimated on the sub sample of individuals in employment is:

$$
\ln Y_{i}=Z_{i} \gamma+\varepsilon_{i}
$$

where $Y$ is the weekly income of individuals. Conventional estimates of the earnings equation can be obtained by treating the sample as if it were comprised of unrelated individuals. Controls for environmental and genetic influences on earnings can be obtained through estimation of fixed effects models on non-identical and identical twins (Ashenfelter and Krueger 1994). ${ }^{19}$

\footnotetext{
${ }^{19}$ Owing to the small sample sizes for the within-twins employment models (see Table 7), a fixed effects selection correction model could not be estimated in this analysis.
} 
The results for the logit model of the determinants of the probability of being employed are presented in Table 6 for the samples of males and females. ${ }^{20}$ In this model the exogenous variables are age and its square, gender, the early school leaver variable used in Section III, two further education variables for, respectively, the possession of trade and university qualifications, marital status and four variables for the family structure, two variables recording the individual's general level of health, a variable for the individual's understanding of the interviewer's questions that might provide a proxy for the person's ability and the 'conduct disorder' variable. The mean rate of employment (the dependent variable) among males is 94 percent and that among females is 72 percent.

In general, the results conform to a priori expectations. For males, age, marital status, health status and 'conduct disorder' are significant determinants of the probability of being employed. As men become older they are less like to be employed. Compared to males who have good/excellent health, those who have fair and poor health are two percentage points and 10 percentage points, respectively, less likely to be employed. ${ }^{21}$ Of special interest to this study is the finding that males who have experienced a large number of childhood conduct disorder problems have a lower probability of being employed. However, the partial effect is very small, being around one percentage point.

\footnotetext{
${ }^{20}$ The $\chi^{2}$ tests of whether the data for males and females could be pooled and a single equation being estimated indicated that these samples should be examined separately.

${ }^{21}$ The partial effect is estimated at the sample mean of employment for males.
} 
Table 6

Models of Employment-Males and Females

\begin{tabular}{|c|c|c|}
\hline \multirow{2}{*}{ Variable } & MALES & FEMALES \\
\hline & Coefficient & Coefficient \\
\hline \multirow[t]{2}{*}{ Constant } & -24.606 & -2.700 \\
\hline & $(2.63)$ & $(0.48)$ \\
\hline \multirow[t]{2}{*}{ Age } & 1.779 & 0.274 \\
\hline & $(2.79)$ & $(0.73)$ \\
\hline \multirow[t]{2}{*}{$\mathrm{Age}^{2} / 100$} & -2.883 & -0.403 \\
\hline & $(2.68)$ & $(0.65)$ \\
\hline \multicolumn{3}{|l|}{ Schooling (Year 11-12, no qualifications) } \\
\hline \multirow[t]{2}{*}{ Early school leavers } & -0.074 & -0.118 \\
\hline & $(0.30)$ & $(0.90)$ \\
\hline \multirow[t]{2}{*}{ Trade qualification } & 0.159 & 0.378 \\
\hline & $(0.61)$ & $(2.75)$ \\
\hline \multirow[t]{2}{*}{ University qualification } & 0.182 & 0.493 \\
\hline & $(0.77)$ & $(4.01)$ \\
\hline \multirow[t]{2}{*}{ Married } & 1.106 & 0.238 \\
\hline & $(5.31)$ & $(1.99)$ \\
\hline \multirow[t]{2}{*}{ Number of children } & 0.126 & -0.665 \\
\hline & $(0.53)$ & $(8.49)$ \\
\hline \multicolumn{3}{|l|}{ Children (No children) } \\
\hline Children between 0 and 5 years & $\begin{array}{r}-0.456 \\
(1.17)\end{array}$ & $\begin{array}{r}-0.999 \\
(7.13)\end{array}$ \\
\hline \multirow[t]{2}{*}{ Children between 6 and 10 years } & -0.435 & 0.167 \\
\hline & $(1.06)$ & $(1.14)$ \\
\hline \multirow{2}{*}{ Children between 11 and 22 years } & 0.826 & 0.433 \\
\hline & $(1.01)$ & $(1.87)$ \\
\hline \multicolumn{3}{|l|}{ Health (Good/excellent health) } \\
\hline Fair health & $\begin{array}{r}-0.426 \\
(1.98)\end{array}$ & $\begin{array}{r}-0.156 \\
(1.17)\end{array}$ \\
\hline \multirow[t]{2}{*}{ Poor health } & -1.702 & -0.356 \\
\hline & $(3.38)$ & $(0.97)$ \\
\hline \multirow[t]{2}{*}{ Fair/poor understanding of interviewer's questions } & -0.386 & -0.084 \\
\hline & $(1.49)$ & $(0.52)$ \\
\hline \multirow[t]{2}{*}{ CONDUCT2 } & -0.170 & -0.127 \\
\hline & $(4.14)$ & $(3.21)$ \\
\hline & 96.70 & 689.28 \\
\hline $\begin{array}{l}\chi^{2}(14) \\
\text { McFadden } R^{2}\end{array}$ & 0.08 & 0.19 \\
\hline Sample size & 2450 & 3088 \\
\hline 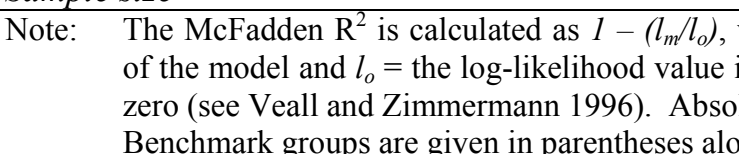 & $\begin{array}{l}=\text { the maxim } \\
\text { intercept coe }\end{array}$ & $\begin{array}{l}\text { kelihood value } \\
\text { re restricted to } \\
\text { theses. }\end{array}$ \\
\hline
\end{tabular}

For females, educational attainment, marital status, children and 'conduct disorder' are the variables that significantly affect their employment chances. For example, compared to females who have completed year 11-12 or have no qualifications, those 
who have a trade or a university qualification are eight percentage points and 10 percentage points, respectively, more likely to be employed. ${ }^{22}$ Married females have an employment rate that is five percentage points higher than those who are not married. However, having children reduces their chances of being employed by 14 percentage points. More specifically, having children between 0 and 5 years reduces a woman's chances of being employed by 20 percentage points. However, having older children (between 11 and 22 years) enhances a woman's chances of being employed by nine percentage points. Similar to the finding for males, females with 'conduct disorder' problems are three percentage points less likely to be employed.

Table 7 shows the coefficients on the 'conduct disorder' variable CONDUCT2 obtained from the various sets of twins analyses for males and females. The employment rate amongst males is 94 percent. The requirement that the employment outcome differs for members of a twin pair for the logit fixed effects model to be estimated effectively precludes this approach, as the sample available for estimation is too small to obtain reliable estimates. This issue does not arise for the female sample, however, where the employment rate is only 72 percent. Hence Table 7 contains estimates of a linear probability fixed effects model for male twins and of both logit and linear probability fixed effects models for female twins.

There is a consistent pattern to the results for females. For both the logit and linear probability between-twins models, there is a strong negative relationship between the probability of being employed and 'conduct disorder'. ${ }^{23}$ As noted previously, this appears to be consistent with the literature. This relationship is reduced to statistical insignificance once family environment factors are held constant in the within-twins estimates obtained using non-identical twins. This would be expected where a favourable environment enhances the chances of being employed, and is associated with fewer childhood behavioural problems. When genetic factors are also held

\footnotetext{
${ }^{22}$ The partial effect is estimated at the sample mean of employment for females.

${ }^{23}$ When the CONDUCT2 measure was replaced with a 'conduct disorder' variable that was computed based only on the four underlying behavioural problems (starting physical fights, staying out later than supposed to, running away from home over night, wagging school), the pattern of findings is the same as reported in Table 7 for the broader measure.
} 
constant through the within-twins estimates obtained using identical twins, there is a positive relationship between early childhood behavioural problems and the chances of being employed.

Table 7

Results From Fixed Effects Models of Effects of Conduct Disorder on Employment - Males and Females

\begin{tabular}{|c|c|c|c|}
\hline \multirow{3}{*}{ Logit: Males } & \multirow[b]{2}{*}{ Between-Twins Model } & \multirow{2}{*}{\multicolumn{2}{|c|}{ Within-Twins Models }} \\
\hline & & & \\
\hline & Individuals & Identical Twins & Non-identical Twins \\
\hline Coefficient & $-0.170(4.14)$ & n.a. & n.a. \\
\hline Partial effect & $-0.010(4.14)$ & n.a. & n.a. \\
\hline Sample size & 2450 & & \\
\hline
\end{tabular}

Linear Probability: Males

\begin{tabular}{|c|c|c|c|}
\hline & Between-Twins Model & & Within-Twins Models \\
\hline & Individuals & Identical Twins & Non-identical Twins \\
\hline Coefficient & $-0.013(4.50)$ & $0.002(0.25)$ & $0.013(1.52)$ \\
\hline Sample size & 2450 & 770 & 658 \\
\hline
\end{tabular}

\begin{tabular}{lrrr}
\hline Logit: Females & & & Within-Twins Models \\
\hline & Between-Twins Model & Identical Twins & Non-identical Twins \\
Coefficient & Individuals & $0.626(2.58)$ & $0.216(0.95)$ \\
Partial effect & $-0.127(3.21)$ & $0.156(2.58)$ & $0.054(0.95)$ \\
Sample size & $-0.026(3.21)$ & 338 & 304
\end{tabular}

Linear Probability: Females

\begin{tabular}{|c|c|c|c|}
\hline & Between-Twins Model & & Within-Twins Models \\
\hline & Individuals & Identical Twins & Non-identical Twins \\
\hline Coefficient & $-0.021(3.25)$ & $0.054(2.71)$ & $0.009(0.41)$ \\
\hline Sample size & 3088 & 1142 & 876 \\
\hline
\end{tabular}

Note: n.a. = not available. Absolute value of ' $\mathrm{t}$ ' statistics in parentheses.

Among males, there is also a negative relationship between 'conduct disorder' and the probability of being employed in the between-twins estimates. Taking account of environmental and genetic factors erodes this relationship, although the findings are based only on a linear probability model.

It is possible that part of the effect of childhood behavioural problems on employment outcomes operate via educational attainment. Hence it is of interest to examine the employment-conduct disorder relationship in models that do not control for educational attainment. The results of this exercise (not reported here) are very 
similar to those reported in Tables 6 and 7. Thus, childhood behaviours are not having any impact on adult employment outcomes via an education channel.

The caveats introduced in Section IV in relation to the interpretation of the results from the application of the within-twins estimator to the study of schooling outcomes carry across the study of the probability of being employed in Table 7. In particular, the within-twins estimates may be subject to attenuation bias associated with measurement error, and this rather than environmental/genetic factors may dominate the Table 7 results. On the surface, however, the Table 7 results indicate that the negative relationship between early childhood behaviours and the chances of being employed that has been reported in the literature is attributable to the environmental and genetic factors that are linked to the childhood behaviours. At least for females, the relationship between early childhood 'conduct disorder' and the chances of being employed net of environmental and genetic factors is positive. This may be because many of the conduct disorders measured here are aggressive behaviours that may help in job search.

An alternative measure of labour market outcome is wages. Table 8 presents the wage results for the samples of males and females. ${ }^{24}$ This model is similar in specification to that used to describe labour force status. However, in this case the age variable is entered in the Gompertz form that is argued to be superior in the study of young workers (Borland and Suen 1994, Griliches 1976). The four variables for children are omitted as these will have most impact on the determination of the composition of the wage and salary sample. Finally, as the dependent variable is weekly income, a variable for part-time work is included in the model. This follows from the analysis of these data by Miller et al. (2003). In this study it is shown that the large coefficient on the part-time work variable is consistent with aggregate-level information on wages in the Australian labour market.

\footnotetext{
${ }^{24}$ The $\chi^{2}$ tests of whether the data for males and females could be pooled and a single equation being estimated indicated that these samples should be examined separately.
} 
Results from two specifications of the earnings model are presented. These differ in the specification adopted for the education variable. In the first, several dummy variables are used for educational attainment. One of these is for early school leaving, and this permit links with the analyses presented in Section III. The second specification replaces the education dummy variables by the continuous education variable used in part of Table 5. This approach will enable links with the studies of twins by Ashenfelter and Krueger (1994), Miller et al. (1995) and others who used a continuous measure of educational attainment. The results from column (i) show that for males, the weekly wage is determined by a number of individual-related characteristics. For example, there is a positive relationship between age and the weekly wage. ${ }^{25}$ With regard to educational attainment, compared to individuals who have completed year 11-12 or those who do not have a qualification, early school leavers earn eight percent less, while those who have a trade qualification and those who have a university qualification earn between seven percent and 33 percent more. The overall impact of educational attainment on wages is around six percent as measured by the continuous education variable (column ii). Married men earn 23 percent more than those who are not married. Men who have poor health or those who have a fair/poor understanding of the interviewer's questions earn less.

Age is insignificant in the earnings function for females, though this is not surprising as the age-earnings profile for adult females is typically quite flat. The results show that compared to females who only completed year 11-12 or those who do not have a qualification, those who have a trade qualification or a university degree earn between 22 percent and 50 percent more. The overall effect of years of education on the earnings of females is nine percent (column iv). Being married considerably disadvantages a woman's earnings. Married women earn 65 percent less than unmarried women. Females who have a fair/poor understanding of the interviewer's questions earn 22 percent less than those who have a good or excellent understanding of the questions asked by the interviewer.

\footnotetext{
${ }^{25}$ The partial derivative $\frac{\partial \ln Y}{\partial A g e}=-0.1 *-8.27 \exp ^{-0.1 \text { Age }}$. Evaluated at Age=30, this equals 0.0412 or 4.12 higher earnings for each extra year.
} 
Table 8

Estimates of Models of Earnings Determination-Males and Females

\begin{tabular}{|c|c|c|c|c|}
\hline \multirow[b]{2}{*}{ Variable } & \multicolumn{2}{|r|}{ MALES } & \multicolumn{2}{|c|}{ FEMALES } \\
\hline & $\begin{array}{r}\text { Coeff. } \\
\text { (i) }\end{array}$ & $\begin{array}{r}\text { Coeff. } \\
\text { (ii) }\end{array}$ & $\begin{array}{r}\text { Coeff. } \\
\text { (iii) }\end{array}$ & $\begin{array}{r}\text { Coeff. } \\
\text { (iv) }\end{array}$ \\
\hline Constant & $\begin{array}{r}6.722 \\
(88.88)\end{array}$ & $\begin{array}{r}6.018 \\
(59.60)\end{array}$ & $\begin{array}{r}5.768 \\
(57.08)\end{array}$ & $\begin{array}{r}4.773 \\
(32.55)\end{array}$ \\
\hline Age $\left(\exp ^{-0.1 * A g e}\right)$ & $\begin{array}{r}-8.27 \\
(7.41)\end{array}$ & $\begin{array}{r}-8.385 \\
(7.53)\end{array}$ & $\begin{array}{r}2.974 \\
(1.85)\end{array}$ & $\begin{array}{r}3.038 \\
(1.90)\end{array}$ \\
\hline Schooling (Year 11-12, no qualifications) & & & & \\
\hline Early school leavers & $\begin{array}{r}-0.075 \\
(1.95)\end{array}$ & n.a. & $\begin{array}{r}-0.056 \\
(0.81)\end{array}$ & n.a. \\
\hline Trade qualification & $\begin{array}{l}0.069 \\
(1.72)\end{array}$ & n.a. & $\begin{array}{l}0.220 \\
(3.41)\end{array}$ & n.a. \\
\hline University qualification & $\begin{array}{l}0.328 \\
(9.01)\end{array}$ & n.a. & $\begin{array}{r}0.497 \\
(8.58)\end{array}$ & n.a. \\
\hline Years of education & n.a. & $\begin{array}{r}0.060 \\
(11.60)\end{array}$ & n.a. & $\begin{array}{r}0.088 \\
(10.88)\end{array}$ \\
\hline Married & $\begin{array}{l}0.227 \\
(7.46)\end{array}$ & $\begin{array}{r}0.227 \\
(7.49)\end{array}$ & $\begin{array}{r}-0.649 \\
(16.24)\end{array}$ & $\begin{array}{r}-0.651 \\
(16.35)\end{array}$ \\
\hline Health (Good/excellent health) & & & & \\
\hline Fair health & $\begin{array}{r}-0.037 \\
(0.88)\end{array}$ & $\begin{array}{r}-0.038 \\
(0.92)\end{array}$ & $\begin{array}{c}0.004 \\
(0.06)\end{array}$ & $\begin{array}{l}0.012 \\
(0.20)\end{array}$ \\
\hline Poor health & $\begin{array}{r}-0.329 \\
(2.24)\end{array}$ & $\begin{array}{r}-0.315 \\
(2.15)\end{array}$ & $\begin{array}{c}-0.066 \\
(0.36)\end{array}$ & $\begin{array}{c}-0.068 \\
(0.36)\end{array}$ \\
\hline Fair/poor understanding of interviewer's questions & $\begin{array}{l}-0.141 \\
(2.82)\end{array}$ & $\begin{array}{r}-0.133 \\
(2.63)\end{array}$ & $\begin{array}{r}-0.220 \\
(2.80)\end{array}$ & $\begin{array}{r}-0.205 \\
(2.60)\end{array}$ \\
\hline Part-time work & $\begin{array}{r}-0.599 \\
(11.40)\end{array}$ & $\begin{array}{r}-0.596 \\
(-11.32)\end{array}$ & $\begin{array}{r}-0.028 \\
(0.64)\end{array}$ & $\begin{array}{r}-0.028 \\
(0.64)\end{array}$ \\
\hline CONDUCT2 & $\begin{array}{r}-0.011 \\
(1.35)\end{array}$ & $\begin{array}{r}-0.010 \\
(1.22)\end{array}$ & $\begin{array}{r}-0.038 \\
(2.22)\end{array}$ & $\begin{array}{r}-0.036 \\
(2.11)\end{array}$ \\
\hline$F(10,2439)$ & 45.02 & & & \\
\hline$F(8,2441)$ & & 56.69 & & \\
\hline$F(10,3077)$ & & & 38.56 & \\
\hline$F(8,3079)$ & & & & 49.03 \\
\hline Adjusted $R^{2}$ & 0.15 & 0.15 & 0.11 & 0.11 \\
\hline Sample size & 2450 & 2450 & 3088 & 3088 \\
\hline
\end{tabular}

While 'conduct disorder' problems do not affect the earnings of males they reduce the earnings of females by four percent. ${ }^{26}$ This effect is modest compared to educational attainment, marital status and other individual-related characteristics. Moreover,

\footnotetext{
${ }^{26}$ When educational attainment was omitted from the across twins equations, 'conduct disorder' has a negative and significant effect on the earnings of males, and a significant negative effect on the earnings of females almost double that reported in Table 8. Hence the impact of 'conduct disorder' on earnings may be operating through the education variables. The difference between this finding and that reported for the study of employment outcomes may reflect the much stronger role that educational attainment plays in earnings determination than it does in the model of the determinants of the probability of being employed.
} 
when a fixed effects (within twins) model was applied to the data for non-identical and identical twins to take account of the environmental and genetic influences that might be related to both earnings outcomes and the likelihood of experiencing conduct disorder problems, the 'conduct disorder' variable was shown not to influence earnings for either males or females. These results are presented in Table 9. ${ }^{27}$ Similar results were found for within twins analyses when the education variable was omitted from the earnings equations.

Table 9

Fixed Effects Estimates of Model of Earnings, Selected Coefficients-Males and Females

\begin{tabular}{|c|c|c|c|c|c|c|}
\hline \multirow[b]{2}{*}{ Variable } & \multirow[b]{2}{*}{$\begin{array}{r}\text { Between } \\
\text { Twins } \\
\end{array}$} & \multicolumn{2}{|r|}{ MALES } & \multicolumn{3}{|c|}{ FEMALES } \\
\hline & & & in Twins & $\begin{array}{r}\text { Between } \\
\text { Twins } \\
\end{array}$ & & in Twins \\
\hline CONDUCT2 & $\begin{array}{r}-0.010 \\
(1.22)\end{array}$ & $\begin{array}{r}\text { Identical } \\
0.001 \\
(0.06)\end{array}$ & $\begin{array}{r}\text { Non- } \\
\text { identical } \\
-0.027 \\
(1.15)\end{array}$ & $\begin{array}{r}-0.036 \\
(2.11)\end{array}$ & $\begin{array}{r}\text { Identical } \\
-0.038 \\
(0.60)\end{array}$ & $\begin{array}{r}\text { Non- } \\
\text { identical } \\
-0.047 \\
(0.71)\end{array}$ \\
\hline Sample size & 2450 & 770 & 658 & 3088 & 1142 & 876 \\
\hline
\end{tabular}

Note: n.a. $=$ not applicable. Absolute value of ' $\mathrm{t}$ ' statistics are in parentheses.

\section{CONCLUSION}

This study examines the links between childhood 'conduct disorder' problems and schooling and labour market outcomes. It shows that these types of problems can adversely affect an individual's schooling outcome as well as their performance in the labour market. These results are consistent with the limited evidence in the area.

In relation to the schooling outcomes, individuals who had a large number of 'conduct disorder' problems are more likely to leave school before completing years 11 or 12 . However, certain conduct disorder problems are more detrimental to schooling outcomes than others. More specifically, stealing with confrontation, running away from home over night, bullying and starting physical fights are the behavioural problems that have the largest negative impacts on the school leaving decisions of males and females. Analyses of within-twins samples of identical twins suggest that

\footnotetext{
${ }^{27}$ These results may also be subject of the measurement error and omitted variables bias discussed in recent studies (see, for example, Neumark 1999).
} 
genetic factors are the dominant factors which drive the positive association between 'conduct disorder' and early school leaving for both males and females. These results suggest that any policies which aim to encourage individuals to stay on at school must focus not only on the behaviours of the individuals but also on their socioeconomic background.

Individuals who experienced childhood 'conduct disorder' problems are disadvantaged in the labour market compared to those who do not exhibit these characteristics. For example, males and females who experienced 'conduct disorder' problems are less likely to be employed. The impact of childhood 'conduct disorder' problems on the probability of being employed is of the same order of magnitude as that of educational attainment. Analyses of within-twins samples suggest that genetic and environmental factors are the forces which drive the negative relationship between 'conduct disorder' and employment. The potential shortcomings of withintwins analysis identified in recent studies, particularly those associated with measurement error and individual components of ability that are not controlled for when using identical twins, are important caveats on these results.

From the social perspective it will also be useful to expand the set of outcomes considered in this paper. For example, conduct disorder problems may be associated with early involvement with alcohol and drugs. This involvement may be an intermediary that leads to other outcomes, such as early school leaving and poor labour market outcomes. If these links can be quantified then it would widen the scope of the policy measures that might be used to address early school leaving behaviour. 


\section{APPENDIX A \\ DEFINITIONS OF VARIABLES}

\section{Dependent Variable}

Early school leavers: This is a dichotomous variable and is set equal to unity if the individual left school at year 10 or earlier.

Years of Education: This is a continuous variable and measures the number of years of the individual's educational attainment.

Employed: This is a dichotomous variable and is set equal to unity if an individual is employed.

Weekly wage: This is a continuous variable and is computed from the individual's contribution to the weekly combined household income. For weekly income the midpoint of each band was used to construct a continuous measure of income. The open-ended upper limit was given a value 1.5 times the lower threshold level. The dependent variable used in this study is the natural logarithm of weekly wage.

Independent Variables

Female: This is a dichotomous variable and is set equal to unity if the individual is female. Males are assigned a value of zero.

Age: This is a continuous variable and measures the individual's age.

Years of Education: This is a continuous variable and measures the individual's years of educational attainment.

Trade qualification: This is a dichotomous variable and is set equal to unity if the individual has completed year 11-12 and an apprenticeship or diploma.

University qualification: This is a dichotomous variable and is set equal to unity if the individual has a degree from a technical or teacher's college, a university first degree or a post-graduate degree.

Father's post-secondary qualification: This is a dichotomous variable and is set equal to unity if the father has a degree from a technical or teacher's college, a university first degree or a post-graduate degree.

Mother's post-secondary qualification: This is a dichotomous variable and is set equal to unity of the mother has a degree from a technical or teacher's college, a university first degree or a post-graduate degree.

Number of siblings: This is a continuous variable and measures the number of brothers or sisters the individual has. The number of siblings includes the individual's co-twin. 
Married: This is a dichotomous variable and is set equal to unity if the individual is currently married, has ever been married or is currently living with someone as though he/she is married.

Number of children: This is a continuous variable and measures the number of children.

Children between 0 and 5 years: This is a dichotomous variable and is set equal to unity if the individual has a child between 0 and 5 years old.

Children between 6 and 10 years: This is a dichotomous variable and is set equal to unity if the individual has a child between 6 and 10 years old.

Children between 11 and 22 years: This is a dichotomous variable and is set equal to unity if the individual has a child between 11 and 22 years old.

Fair health: This is a dichotomous variable and is set equal to unity if the individual has fair health.

Poor health: This is a dichotomous variable and is set equal to unity if the individual has poor health.

Fair/poor understanding of interviewer's questions: This is a dichotomous variable and is set equal to unity if the individual has a fair or poor understanding of the questionnaires when interviewed.

Part-time work: This is a dichotomous variable and is set equal to unity if the individual works part-time.

CONDUCT1: This is a continuous variable and measures the number of behavioural problems exhibited by the individual. It is constructed by summing occurrences of (i) bullying, deliberately hurting or being mean to others; (ii) starting physical fights (with persons other than brothers or sisters) three or more times; (iii) using a weapon to threaten or harm someone; (iv) causing physical injuries to anyone on purpose; (v) cruelty or being mean to animals on purpose; (vi) stealing by threatening or using force; (vii) forcing someone into intercourse or other form of sexual activity; (viii) deliberately lighting fires with the intention of causing damage; (ix) damaging someone's property on purpose; (x) breaking into someone's car or house or anywhere else; (xi) lying, using a false name or alias, or outsmarting and conning others; (xii) stealing money or things from family, shoplifting from shops or from other people, or forging anyone's signature on a cheque or credit card, more than once; (xiii) often staying out much later than supposed to or often sneaking out of the house at night (requiring the onset to be before 13 years of age); (xiv) running away from home overnight; and (xv) wagging school for an entire day at least twice in one years (requiring the onset to be before 13 years of age). 
CONDUCT2: This is a continuous variable and measures the number of behavioural problems exhibited by the individual. It is constructed by adding occurrences of (i) CONDUCT1; (ii) often staying out much later than supposed to or often sneaking out of the house at night (not requiring the onset to be before 13 years of age); and (iii) wagging school for an entire day at least twice in one year (not requiring the onset to be before 13 years of age); and subtracting occurrences of (i) often staying out much later than supposed to or often sneaking out of the house at night (requiring the onset to be before 13 years of age); and (ii) wagging school for an entire day at least twice in one year (requiring the onset to be before 13 years of age). 


\section{Table A1}

Means and Standard Deviations of Variables_-Males and Females

\begin{tabular}{lrrrr}
\multicolumn{4}{c}{ Means and Standard Deviations of Variables-Males and Females } \\
\hline Variable & & MALES & \multicolumn{3}{c}{ FEMALES } \\
& Mean & Std.Dev & Mean & Std.Dev \\
Age (years) & 29.85 & 2.43 & 29.91 & 2.48 \\
Father's post-secondary qualification (\%) & 23.53 & 42.43 & 21.59 & 41.15 \\
Mother's post-secondary qualification (\%) & 19.38 & 39.54 & 16.77 & 37.37 \\
Number of siblings & 2.36 & 1.88 & 2.33 & 1.82 \\
CONDUCT1 & 0.91 & 1.43 & 0.33 & 0.80 \\
CONDUCT2 & 1.51 & 1.76 & 0.74 & 1.15 \\
Early school leavers (\%) & 21.59 & 41.16 & 19.44 & 39.58 \\
& & & & \\
Sample size & 2533 & & 3154 & \\
\hline
\end{tabular}




\section{REFERENCES}

Ashenfelter, O. and Krueger, A.B., (1994). "Estimates of the Economic Return to Schooling from a New Sample of Twins". American Economic Review. 84:1157-1173.

Australian Institute of Multicultural Affairs, (1985). Reducing the Risk: Unemployed Migrant Youth and Labour Market Programs, Australian Institute of Multicultural Affairs, Melbourne.

Baker, L.A., Treloar, S.A., Reynolds, C., Heath, A. and Martin, N.G., (1996). "Genetics of Educational Attainment in Australian Twins: Sex Differences and Secular Changes". Behavior Genetics. 26:89-102.

Black, D.A., Berger, M.C. and Scott, F.C., (2000). "Bounding Parameter Estimates with Neoclassical Measurement Error". Journal of the American Statistical Association. 95:739-748.

Borland, J. and Suen, A., (1994). "The Experience-Earnings Profile in Australia". Economic Record. 70:44-55.

Bound, J. and Solon, G., (1999). "Double Trouble: On the Value of Twins-based Estimation of the Return to Schooling". Economics of Education Review. 8:169-182.

Cairns, R.B., Cairns, B.D. and Neckerman, H.J., (1989). "Early School Dropouts: Configurations and Determinants". Child Development. 60:1437-1452.

Caspi, A., Wright, B.R.E., Moffitt, T.E. and Silva, P.A., (1998). "Early Failure in the Labor Market: Childhood and Adolescent Predictors of Unemployment in the Transition to Adulthood". American Sociological Review. 63:424-451.

Farmer, E.M.Z., (1995). "Extremity of Externalizing Behavior and Young Adult Outcomes". Journal of Child Psychology and Psychiatry. 36:617-632.

Feinstein, L., (2000). "The Relative Economic Importance of Academic, Psychological and Behavioural Attributes Developed in Childhood". London School of Economics, Centre for Economic Performance Discussion Paper, No. 443.

Fergusson, D.M. and Horwood, L.J., (1998). "Early Conduct Problems and Later Life Opportunities". Journal of Child Psychology and Psychiatry. 39:1097-1108.

Gregg, P. and Machin, S., (2000). "Child Development and Success or Failure in the Youth Labour Market", in NBER Comparative Labor Market Series, University of Chicago Press, Chicago: 247-288. 
Griliches, Z., (1976). "Wages of Very Young Men”. Journal of Political Economy, 84:S69-S85.

Griliches, Z., (1979). "Sibling Models and Data in Economics: Beginnings of a Survey”. Journal of Political Economy. 87:S37-S64.

Jimerson, S., Egeland, B., Sroufe, A. and Carlson, B., (2000). "A Prospective Longitudinal Study of High School Dropouts, Examining Multiple Predictors Across Development". Journal of School Psychology. 38:525-549.

Le, A.T. and Miller, P.W., (2003). "School Leaving Decisions in Australia: A Cohort Analysis". Education Economics (forthcoming).

Long, M., Carpenter, P. and Hayden, M., (1999). Participation in Education and Training 1980-1994. LSAY Research Report Number 13. Australian Council for Educational Research. Victoria.

Lynskey, M.T., Heath, A.C., Nelson, E.C., Bucholz, K.K., Madden, P.A.F., Slutske, W.S., Statham, D.J. and Martin, N.G., (2002). "Genetic and Environmental Contributions to Cannabis Dependence in a National Young Adult Twin Sample". Psychological Medicine. 32:195-207.

Marks, G.N., Fleming, N., Long, M. and McMillan, J., (2000). Patterns of Participation in Year 12 and Higher Education in Australia: Trends and Issues. LSAY Research Report Number 17. Australian Council for Education Research. Victoria.

Miller, P.W. and Volker, P., (1989). "Socioeconomic Influences on Educational Attainment: Evidence and Implications for the Tertiary Education Finance Debate". Australian Journal of Statistics. 31A:47-70.

Miller, P.W., Mulvey, C. and Martin, N., (1995). "What Do Twins Studies Reveal About the Economic Returns to Education?: A Comparison of Australian and US Findings". American Economic Review. 85:586-599.

Miller, P.W., Mulvey, C. and Martin, N., (2003). "The Return to Schooling: Estimates from a Sample of Young Australian Twins", Mimeo, Department of Economics, The University of Western Australia.

Nelson, E.C., Heath, A. C., Madden, P.A.F., Cooper, M.L., Dinwiddie, S.H., Bucholz, K.K., Glowinski, A., McLaughlin, T., Dunne, M.P., Statham, D.J., Martin, N.G., (2002). "Association Between Self-reported Childhood Sexual Abuse and Adverse Psychological Outcomes". Archives of General Psychiatry. 59:139-145.

Neumark, D., (1999). "Biases in Twin Estimates of the Return to Schooling". Economics of Education Review. 18:143-148. 
Quay, H.C., (1978). “Behavior Disorders in the Classroom”. Journal of Research and Development in Education. 11:8-17.

Rumberger, R.W., (1995). "Dropping Out of Middle School: A Multilevel Analysis of Students and Schools". American Educational Research Journal. 32:583-625.

Veall, M.R. and Zimmermann, K.F., (1996). "Pseudo-R ${ }^{2}$ Measures For Some Common Limited Dependent Variable Models". Journal of Economic Surveys. 10:241-259.

White, H., (1980). “A Heteroscedasticity Consistent Covariance Matrix Estimator and a Direct Test of Heteroscedasiticy". Econometrica. 48:817-818.

Williams, T., Harsel, Y., Clancy, J., Miller, H. and Greenwood, C., (1987). Participation in Education. Monograph Number. 30. Australian Council for Educational Research. Victoria. 